\title{
Research on the Cross-Level Effect of Spiritual Leadership to Employees' Creativity
}

\author{
Wang Xinyu, Deng Zhihua* \\ School of Business Administration, Guizhou University of Finance and Economics, Guiyang, Guizhou
}

Keywords: spiritual leadership, workplace spirituality, employee creativity

\begin{abstract}
Employee creativity has important significance for the organizational development and growth of employees. This paper analyzed the effect and mechanism of spiritual leadership through the workplace spirituality to employee creativity. By the hierarchical statistical analysis of 192 sets of valid supervisor-employees questionnaire data, the results show that spiritual leadership significantly and positively affects creativity, workplace spirituality and also show that workplace spirituality has hierarchical intermediary effect between the impact of spiritual leadership to employee creativity. It has important enlightenment to improve the leadership effectiveness of spiritual leadership and motivate the employee creativity.
\end{abstract}

\section{Introduction}

The importance of creativity in an organization is obvious: employee creativity is fundamental to creating value for customers. Technicians need to use creativity to develop new products, to invent and innovate to bring about technological innovation. Sales people need to use creativity to open up the market, expand sales channels, look for sales opportunities to create more sales, and so on. As a result, employee creativity is receiving more and more attention as a key work output.

As an emerging cross-research theme of spirituality, positive psychology and leadership, spiritual leadership includes the values, attitudes and behaviors that are necessary to meet the mental needs and mental health of employees. And it can strengthen the mental strength of employees, have a unique effect on addressing the current spiritual problems like spiritual emptiness, loss of faith and value disorder. So it has been paid great attention by the academic circles, and it is a new and important subject at home and abroad. This study focuses on the following two questions: (1) How effective is China's spiritual leadership in the process of influencing employee creativity? (2) What is the process and internal mechanism of the role of spiritual leadership in our country to the creativity of employees?

\section{Documentary Review and Research Hypothesis}

\subsection{The influence of spiritual leadership on employee creativity}

According to Fry [1], spiritual leadership is a way of leadership that must be based on the values, attitudes, and behaviors that inspire oneself and others and make them spiritually present based on a sense of mission and identity. It include dimensions such as vision, hope/belief, altruise love, and so on. It is also pointed out that the purpose of spiritual leadership is to build motivational visions and values and foster a high level of organizational commitment and productivity. According to Amabile et al (1996) [2], creativity is the ability of a member or team to come up with new and practical ideas or solutions for enterprise products, services, and management processes. After summarizing the factors that influence creativity, Mumford [3] found that leadership is still an important factor in employee creativity. Therefore, employees need an internal, sustained motivation to inspire themselves in order to be more creative. And spiritual leadership can bring spiritual support and spiritual strength to employees, thereby encouraging employees to have a stronger internal motivation and sense of responsibility to participate in creative activities. Amabile [2] found that the use of individual creativity in an organization is significantly positively correlated 
with leadership encouragement. Pandey et al [4] found that spiritual leadership had a significant direct impact on the team's creative atmosphere. Rollins and Fry [5] studied how much spiritual leadership can improve the performance of innovative and risky IT projects in the U.S. federal government, and the results show that spiritual leadership is positively influencing the organizational commitment, productivity, creativity and project performance of IT project personnel. Based on the above analysis, it is proposed that:

Hypothesis 1 (H1): Spiritual leadership is positively affecting employee creativity

\subsection{The Influence of spiritual leadership on workplace spirituality}

Workplace spirit emphasizes the employee's spiritual experience at work and the value of exploring work and its importance to the profession. Ashmos and Duchon [6] pointout that the employee's inner spiritual life enables them to discover the value of work, and is also supported and nurtured by the process of discovering the value of the work. Employees can bring a complete and comprehensive self to work that fully demonstrates their creativity, emotions, and intelligence. and have the opportunity to show many aspects of their lives. A survey of 141 employees of public health organizations by Frew [7] found that the organizational stressors and mental stress perceived by business leaders had a negative primary effect on workplace psychosis. That is, the leader's mental stress load status has a significant negative impact on workplace mentality. Sanders III et al showed that spiritual leadership had a significant causal impact on workplace spirit and organizational commitment through a study of a sample of 225 general employees in non-profit medical institutions. Research by Phipps [8] shows that the spiritual beliefs of business leaders influence their own information screening and knowledge re-engineering, as well as the strategic decisions and spiritual atmosphere of the company. Based on the above analysis, it is proposed that:

Hypothesis 2 (H2): Mental leadership is positively affecting the mentality of the workplace

\subsection{The intermediary role of workplace spirituality}

Ashmos \& Duchon [6] believed that workplace spirit can effectively bring the employee's actions, cognition and spirit into internal harmony. Darby \& James [9] believed that workplace spirit can accommodate individual spiritual differences among members of different organizations, and that this atmosphere of encouraging differences can stimulate employees' creativity and creativity Whitaker \& Westerman [10] believed that workplace spirituality and organizational values internalization led to a higher level of individual initiative, and the psychological empowerment part mediated the impact of workplace spirit on individual initiative and fully intermediary the influence of organizational value internalization on individual initiative spirit, which shows that workplace spirit and organizational value internalization are the key pre-factor variables of individual initiative spirit. This suggests that workplace spirit is likely to be an important bridge between the creativity of the mental leadership. Therefore, based on the above analysis, it is proposed that:

Hypothesis 3 (H3): Workplace spiritual intermediary the positive influence of spiritual leadership on employee creativity

The above research content and their relationships are shown in Figure 1.

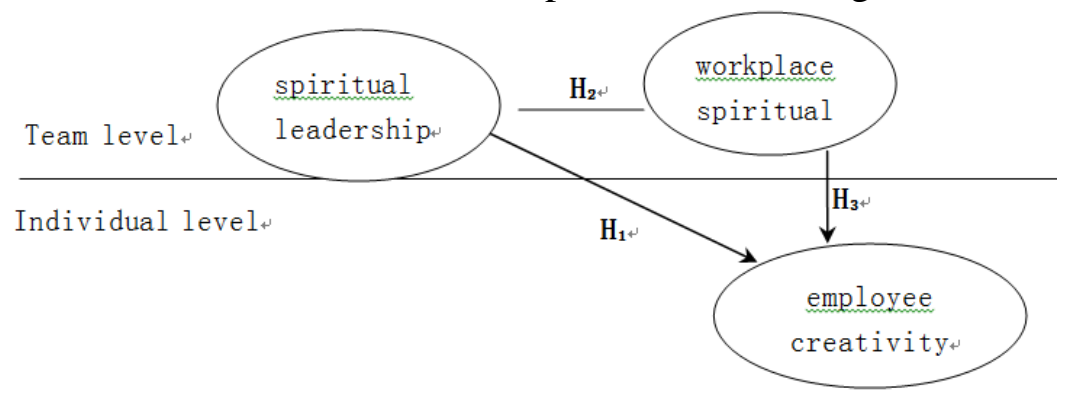

Figure 1 Research content and their relationships 


\section{Research Design}

\subsection{Procedures and Samples}

Using the supervisor-employee matching survey method to collect data, in Guiyang, Chengdu, Xi'an and other three cities' enterprise, distribute 284 sets of questionnaires. After the elimination of fill-in waste paper, the successful support of the effective questionnaire are 192 sets, the total recovery rate of the questionnaire is $67.61 \%$. A total of 425 employees and supervisors come from 32 enterprises participated in the survey, involving different industries and enterprises, so the distribution of enterprise samples is reasonable and highly representative.

\subsection{Variable measurement}

Spiritual leader uses a scale developed by Fry et al (2005) [11], which has three dimensions: vision, hope/belief, and altruistic love, including "my boss has a strong sense of mission in the job," "my boss has confidence in the vision of the organization", and "my boss is very friendly and considerate of his subordinates." Workplace spirit use a scale developed by Ashmos and Duchon [6]which consist of three dimensions: self-spiritual life, finding work value and team spirit, including "caring for the mental health of colleagues," "understanding the meaning of work" and "working together to resolve conflicts in a positive way at work. Creativity uses a scale developed by Zhou and George [12], which is a single-dimensional scale that includes 11 questions. The questionnaire uses a 5-point score from the Licht scale, with 1 point indicating "total disapproval", 2 points indicating "comparative disapproval", 3 points indicating "neutrality", 4 points indicating "comparative consent" and 5 points for indicating "total consent". Common demographic characteristics such as gender, age (segment), education level, and age are used as control variables.

\section{Data Analysis}

\subsection{Reliability and validity analysis}

Cronbach's alpha coefficient for spiritual leadership, workplace spirituality and employee creativity are $0.767,0.749,0.828$, which calculated with SPSS17.0 software. That indicate that the data is highly reliable and meets the requirements of statistical testing.

Because use the more mature scale that developed by foreign scholars and many times to use, use LISREL8.70 software for validation factor analysis of the validity of the variables. According to Qiu Haozheng, Lin Bifang, use fitting indicators such as s2/d, SRMR, AGFI, RMSEA, NNFI, CFI and their corresponding critical to judge, and the indicators of each variable and its values are marked in Table 1.

Table 1 Confirmatory factor analysis indicators and values of each scale

\begin{tabular}{|c|c|c|c|c|c|c|}
\hline & $\chi 2 / \mathrm{d} f$ & SRMR & AGFI & RMSEA & NNFI & CFI \\
\hline spiritual leadership & 3.258 & 0.053 & 0.894 & 0.084 & 0.951 & 0.848 \\
\hline workplace spirit & 3.513 & 0.049 & 0.894 & 0.104 & 0.934 & 0.924 \\
\hline employee creativity & 3.268 & 0.047 & 0.847 & 0.084 & 0.915 & 0.875 \\
\hline
\end{tabular}

note: ${ }^{*} \mathrm{p}<0.05,{ }^{*} \mathrm{p}<0.01$, the diagonal brackets are the Cronbach's $\alpha$ coefficients of each variable

From Table 1, it is learned that the majority of the AGFI, NNFI, CFI indicator values of each variable exceed 0.9 requirements, most variables of the RMSEA value is less than 0.1 , most variables SRMR value is less than 0.05 , which means the validity of the variables index value reached or close to the required critical value, fit condition is better, meet data quality requirements.

\subsection{Related analysis}

Using SPSS17.0 software to do related analysis, the specific values of the mean, standard deviation and related coefficients of each variable are detailed in Table 2. 
Table 2 Mean, standard deviation and correlation coefficient of variables

\begin{tabular}{|c|c|c|c|c|c|}
\hline $\begin{array}{c}\text { employee } \\
\text { creativity }\end{array}$ & Mean & S.D. & 1 & 2 & \\
\hline $\begin{array}{c}\text { spiritual } \\
\text { leadership }\end{array}$ & 3.4578 & .75874 & $(.767)$ & & \\
\hline workplace spirit & 3.2367 & .72567 & $.408^{* *}$ & $(.749)$ & \\
\hline $\begin{array}{c}\text { employee } \\
\text { creativity }\end{array}$ & 3.7594 & .75867 & $.468^{* *}$ & $.452^{*}$ & $(.828)$ \\
\hline
\end{tabular}

From Table 2, spiritual leadership is positively correlated with workplace spirit and creativity, and the correlation coefficients are $0.457(\mathrm{p}<0.01), 0.408(\mathrm{p}<0.01), 0.468(\mathrm{p}<0.01)$. In addition, workplace spirit is positively correlated with creativity and the coefficients are $0.348(\mathrm{p}<0.05)$ and $0.452(\mathrm{p}<0.05)$, which make it a partial condition for the hypothesis test.

\subsection{Aggregate analysis}

Since all data are individually reported, but spiritual leadership and workplace spirit are defined at the organizational level, data needs to be aggregated and analysed. Intra-group consistency (Rwg) and intergroup variability (ICC) of variable data need to be examined before data at the individual level is aggregated into data at the organizational level. The values of spiritual leadership and workplace spirituality ICC 1, ICC2 and Rwg are calculated, as detailed in Table 3.

Table 3 Rwg, ICC1, ICC2 index values of spiritual leadership and workplace spirituality

\begin{tabular}{|c|c|c|c|}
\hline & ICC 1 & ICC2 & $\mathrm{R}_{\text {wg }}$ \\
\hline spiritual leadership & 0.23 & 0.54 & 0.75 \\
\hline workplace spirituality & 0.19 & 0.51 & 0.78 \\
\hline
\end{tabular}

\subsection{Hypothetical test}

First of all, the effect of the direct influence of spiritual leadership on variables is tested, and the theory of structural equation model is used to analyze LISREL8.70 software, which is shown in Figure 2.

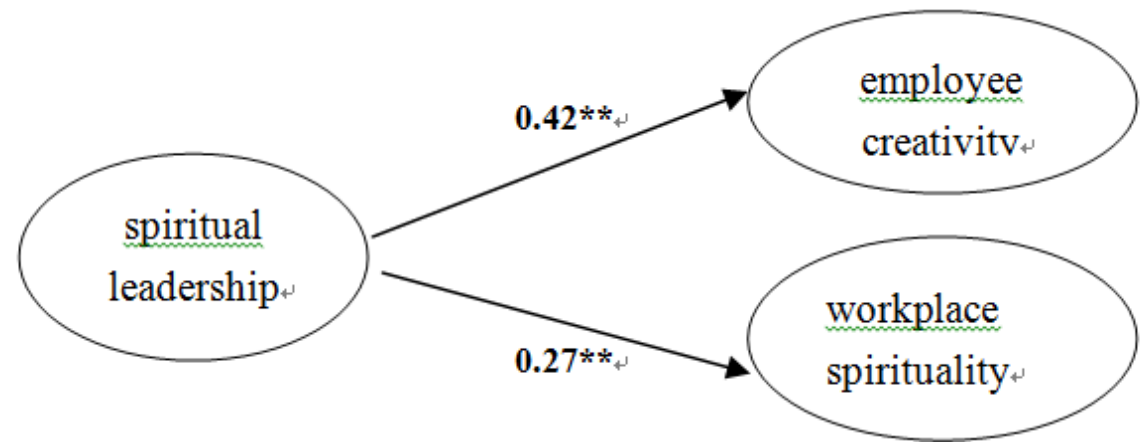

Figure 2 Model diagram of direct effects of spiritual leadership

The results show that spiritual leadership is positively affecting creativity ( $\beta=0.42, \mathrm{P}<0.01$ ), Hypothesis 1 is validated, is positively affecting workplace spirituality $(\beta=0.27, P<0.01$ ), Hypothesis 2 is validated.

Test cross-level mediation effects based on the methods and steps described by Kreft and Leeuw . From the above analysis, it can be seen that independent variable spiritual leadership is significantly positively correlated with dependent variable creativity, and spiritual leadership is positively affecting creativity; workplace spirituality is significantly correlated with dependent variable creativity; Independent-variable spiritual leadership is significantly positively correlated with intermediary-variable workplace spirituality, and independent-variable spiritual-leadership positively affects intermediary-variable workplace mentality. 
HLM6.0 statistical analysis software was used to complete the testing of the intermediary effects across levels. Divided into following three steps: First, test the cross-level direct effect of spiritual leadership on creativity; second, test the cross-level direct effect of spirituality on creativity in the workplace; The following is a cross-level intermediary model of workplace spirituality:

Table 4 Test results of cross-level mediation effects

\begin{tabular}{|c|c|c|c|c|}
\hline \multirow{2}{*}{$\begin{array}{c}\text { Independent } \\
\text { variable }\end{array}$} & \multirow{2}{*}{$\begin{array}{c}\text { Mediation } \\
\text { variable }\end{array}$} & \multicolumn{3}{|c|}{ Dependent variable(creativity) } \\
\cline { 3 - 5 } & Step1 & Step2 & Step3 \\
\hline $\begin{array}{c}\text { spiritual } \\
\text { leadership }\end{array}$ & $\begin{array}{c}\text { workplace } \\
\text { spirituality }\end{array}$ & $0.42^{* *}$ & $0.28 *$ & $0.18^{*}$ \\
\hline
\end{tabular}

Table 4 shows that when the spirit of the workplace is not added, the influence of spiritual leadership on creativity is $0.42(\mathrm{p}<0.01)$ in Step1, and after adding the workplace spirit, the influence of spiritual leadership on creativity has been reduced from $0.42(p<0.01)$ in Step1 to 0.18 $(p<0.05)$, which indicates that spiritual leadership in the workplace intermedia the influence of spiritual leadership on creativity, which have across-levels intermediary effect. Hypothesis 3 is validated.

\section{Conclusion, Discussion and Outlook}

\subsection{Conclusion and discussion}

Following the spiritual research perspective (spiritual leadership and workplace spirituality), this paper analysis the influence effect of spiritual leadership from the workplace spirit at the team level on employee creativity, construct the multi-level theoretical model by integrating individual-team-level variables. The theory of structural equation model and the technique of cross-level research are verified. The results show that spiritual leadership is positively affecting creativity and workplace spirit, and workplace spirituality has a cross-level intermediary effect in the process of influencing employee creativity in the process of spiritual leadership.

\subsection{Limitations and outlook}

First of all, the theoretical analysis is not deep enough to be close. Because the research on related concepts and theories is still in its infancy, and the relevant literature is also lacking, it is still not close enough to infer the relationship between concepts. With the continuous development of spiritual leadership and workplace spiritual research in the academic circles at home and abroad, the logical relationship between them will become clearer.

Second, the local scale is underused. $\mathrm{n}$ order to suit the economic and social cultural background of our country, the above scale developed by foreign scholars should be scientifically revised and adjusted according to the research design and actual situation, which can further improve the credibility and validity of the research.

Finally, the adjustment factors that mental leadership affects employee creativity are not taken into account. The influence of superior leadership on employee behavior is disturbed and restricted by many other factors, and the future research and design can be further situational, taking full account of the adjustment of relevant factors.

\section{Acknowledgments}

This work was supported by the National Natural Science Foundation of China (71962003).

\section{References}

[1] Fry, L, W. (2003) Toward a theory of spiritual leadership. Leadership Quarterly, 14, 693-727.

[2] Amabile, T, M, Conti,R.,Coon,H.,Lazenby,J.,Herron,M.(1996)Assessing the work environment for creativity. Academy of Management Journal, 39(5), 1154-1184. 
[3] Mumford, M.D., G. M. Scott, B., Gaddis, et al. (2002) Leading creative people: orchestrating expertise and relationship. Leadership Quarterly, 13(6), 705-750.

[4] Pandey, A., Chattopadhyay, D., Bose, S. (2013) Impact of spirituality of leaders at work and leaders' reputation on teams' spiritual climate. Academy of Management, Annual Meeting Proceedings.

[5] Rollins, R., Fry, L, W. (2013) Impact of spiritual leadership on the performance of information technology projects. Academy of Management. Annual Meeting Proceedings.

[6] Ashmos, D, P., Duchon, D. (2000) Spirituality at work: a conceptualization and measure. Journal of Management Inquiry, Vol. 9 No. 2,134-45.

[7] Frew, E, J., Stressors. (2000) strain, and spirituality at work. Doctoral Dissertation, New Mexico State University, 413.

[8] Phipps, K, A. (2012) Spirituality and strategic leadership: The influence of spiritual beliefs in decision making. Journal of Business Ethics, Vol.106, No. 2, 177-189.

[9] Darby, P., James, V. (2011) Emergent strategy in a global community of religious sisters and leading organizational change through practical spirituality: a case study in two parts. International Journal of Leadership in Public Services, Vol.7. No. 2, 151 - 165.

[10] Whitaker, B., Westerman, J, W. (2013) Linking spirituality and values to personal initiative through psychological empowerment. Academy of Management Annual Meeting Proceedings.

[11] Fry, L, W., Vitucci, S., Cedillo, M. (2005) Spiritual leadership and army transformation: theory, measurement, and establishing a baseline. The Leadership Quarterly, 16(5), 835-862.

[12] Zhou, J., George, J, M. (2001) When job dissatisfaction leads to creativity : encouraging the expression of voice. Academy of Management Journal, 44, 682-696. 